\title{
Integrated Information System for The Older People With A Comprehensive Care Delivery Approach
}

\author{
Hamid Moghaddasi ${ }^{1 *}$, Mahnaz Hamedan ${ }^{1}$, Farkhondeh Asadi ${ }^{1}$, Hassan Emami ${ }^{1}$ and Forough \\ Rahimi $^{2}$ \\ ${ }^{1}$ Department of Health Information Technology and Management, Faculty of Paramedical Sciences, Shahid Beheshti University of Medical Sciences, \\ Tehran, Iran \\ ${ }^{2}$ Department of English Language, Faculty of Paramedical Sciences, Shahid Beheshti University of Medical Sciences, Tehran, Iran
}

*Corresponding author: Hamid Moghaddasi, Associate Professor of Health Information Management \& Medical Informatics, Iran.

To Cite This Article: Hamid Moghaddasi. Integrated Information System for The Older People With A Comprehensive Care Delivery Approach. Am J Biomed Sci \& Res. 2019 - 2(6). AJBSR.MS.ID.000613. DOI: 10.34297/AJBSR.2019.02.000613

Received: April 01, 2019 | Published: May 02, 2019

\begin{abstract}
Introduction: The number of older people is on a quick rise due to increased social welfare, improved health and economic indices, and increased life expectancy. Considering the older adults' dominating social and health conditions, there is a constant need for a wide range of care and social services. The integrated and continuous care for the older adults play a crucial role in better management, improved service delivery quality, optimal use of health resources, and reduced cost. Developing an integrated information system is a proper strategy in realizing continuous and comprehensive care for the older adults. Thus, the present study aims at investigating the integrated information systems of the older adults and its significance in realizing/providing comprehensive care to them.
\end{abstract}

Methods \& Materials: In this review study, published studies from 1990 to 2017 were analyzed. In order to search articles, the author evaluated and reviewed valid scientific journals, websites and databases such as PubMed and Google Scholar, and found 243 articles. Having studied the titles and abstracts of the article in terms of relativeness to the research purpose, a precise review of the content of the articles was conducted. Eventually 30 studies were selected based on the specified criteria.

Results: Based on the results, using information systems plays a key role in realizing comprehensive care of the older adults and leads to better management of the older adults, provision of quality services and reduced costs. Based on the investigations, the integrated information system of the older people requires some features, namely, accessibility to comprehensive information, support for integrated care of the older adults, the ability to share information and developing an integrated electronic record for them.

Conclusion: The main component and infrastructure for the comprehensive care program for the elderly includes implementing an information system for them. Regarding the increasing growth of older adults' population in societies, it deems necessary to design and implement an integrated information system for them. Developing a comprehensive information infrastructure and determining the architecture of the information system for the older adults is an important issue that can be effective in developing a principled and efficient information system design.

Keywords: Older adults; Elderly; Integrated care; Geriatric; Integrated information system

\section{Introduction}

Nowadays, the number of older people is quickly on the rise due to increased social welfare, improved health and economic indices, and increased life expectancy [1-3]. Aging is the most important anthropological phenomenon of the late 20th century and the beginning of the 21st century [1]. According to the definition of the World Health Organization, anyone with the age above 60 years is considered to be elderly [1,2]. According to statistics by the United Nations in 2015, about 900 million people (12\% of the world's population) are elderlies, and it has been estimated to rise to 1.4 billion and 2.1 billion in years 2030 and 2050, respectively (26\%)
$[3,4]$. The progressive increase in the aging population imposes many health, economic and social problems on societies [5].

Physical and mental capacities would be reduced in senility; therefore, the diversity and multiplicity of diseases would be raised in these ages. Also, during this period, a variety of diseases and psychological problems threaten senile that would result many problems in their life [6,7]. According to study results, more than $50 \%$ of elderly suffer from various types of acute and chronic diseases that lead them to functional disabilities $[4,8]$. 
Given the prevailing social and health conditions for elderly, these people continuously require a wide range of care and social services [4,7,9-11]. The provision of integrated and comprehensive health care services for elderly has a crucial role in the improvement of their quality of care, optimized use of health resources and reduction of costs [6,11-13].

Nowadays, integrated and comprehensive care of elderly is one of the important issues in the health system. Developed countries have identified the integrity of care as a key factor in improving the quality of healthcare and increasing system efficiency $[14,15]$. To provide health and social services to elderly, individuals and different organizations such as hospitals, welfare organizations, nursing care centers, elderly counseling centers, rehabilitation centers and psychological centers are involved. In addition, municipality, the pension fund and the transportation organization also provide services for improving the social welfare of elderly. To provide an integrated and comprehensive service to elderly, organizations and care providers must communicate with each other effectively and consistently [7,16-18]. In this regard, information systems can play a significant role in establishing effective communication between providers, improving coordination and facilitating the exchange of information between organizations $[4,7,19,20]$. It also reduces medical errors, increases patient safety, improves care, reduces costs, and generally improves the quality of care [21]. Using the information system, the care team can access information about elderly and share existing experiences which will result in appropriate decision makings and the provision of high quality services to elderly [4,5,7,9,22-24]. In general, the creation and development of integrated information systems can be a reasonable method to provide continuous and comprehensive care to elderly $[7,10,13,25]$. Therefore, this study reviewed the integrated information systems of elderly and their impacts on implementing comprehensive and continuous care in this section.

\section{Methods}

In this review study, published studies from 1990 to 2017 were analyzed. In order to search articles, the author evaluated and reviewed valid scientific journals, websites and databases such as PubMed, EBSCO Host, Web of science, and Google Scholar and used a variety of keywords, namely, geriatrics, elderly people, information system, integrated care, comprehensive health care, continuing care and aging health, resulting in the selection of 243 articles. (Figure 1) presents the process for identifying and extracting studies.

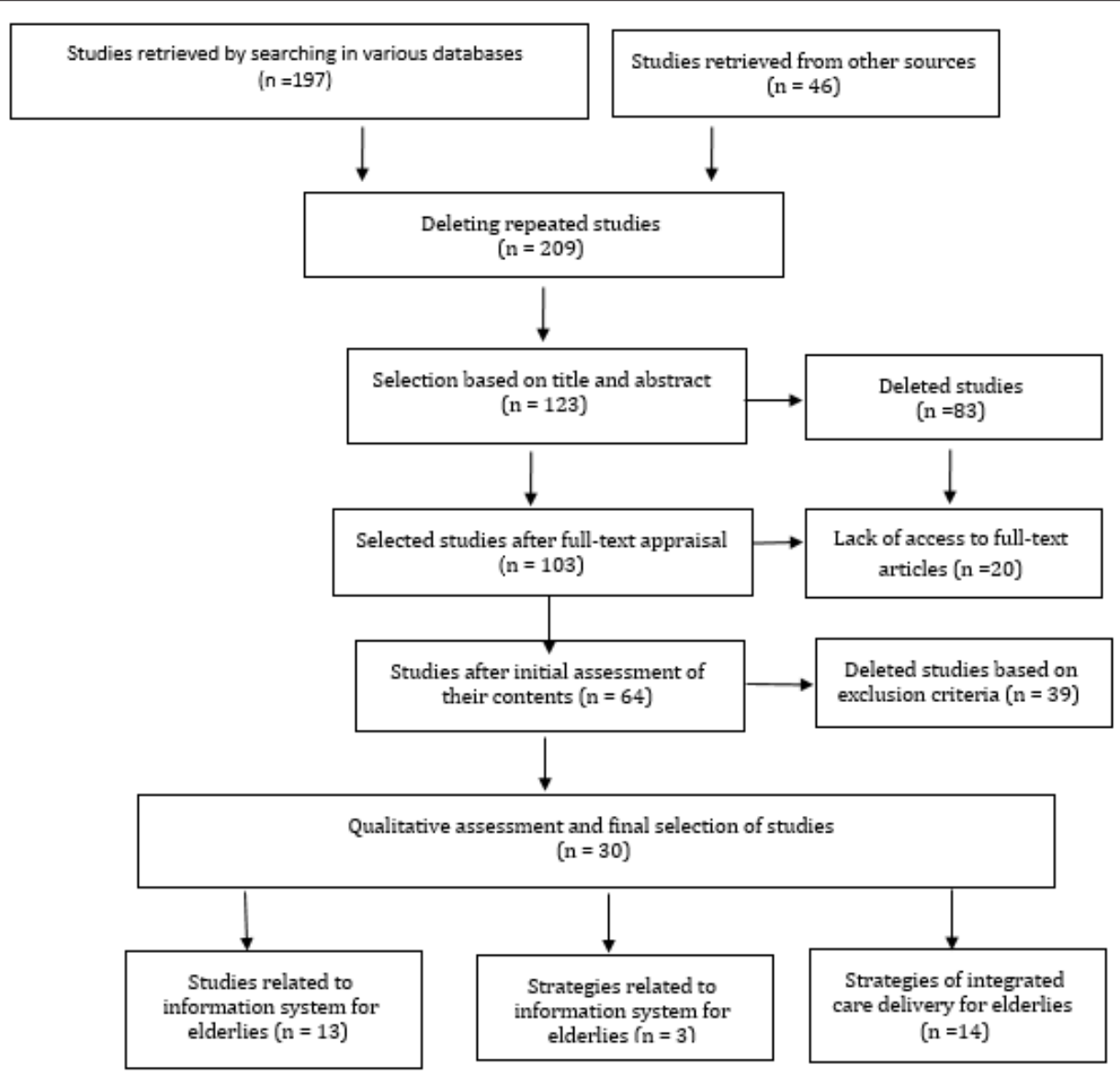

Figure 1: The process of identifying and extracting studies.

Having studied the title and abstract of the article in terms of relativeness to the research purpose, the author removed a number of repetitive articles and those with no full accessibility. Then, the content of the articles were precisely investigated and based on the specified criteria, eventually 30 studies related to the research purpose were selected. Inclusion criteria were determined as studies on the information programs for elderlies; programs on the integrated care for the older adult; studies on the elderlies' 
information system; and studies on the effect of employing the elderlies' integrated information system. Exclusion criteria included: integrated care programs for non-older adult; studies on the use of information technology in the older adult; information systems irrelevant to the elder people; and non-English studies.

\section{Background}

Officials have determined programs and policies to develop older adults' information systems at the national level regarding the significance and necessity of the information systems for elderlies in countries such as UK, Ireland and New Zealand. The details of such programs are elaborated below:

\section{Older people's information system in England}

In 2000, to provide high-quality, socially-based services for the older people, the U.K. Department of Health developed a comprehensive program called NSF(National Service framework) [26]. The program generally aimed to deliver standard care services, further access to services, reduce unnecessary visits, manage chronic illnesses, enhance life expectancy and promote dignity, security, lifestyle and independence of the older peoples [26]. In regard with delivering care services, NSF strategy specified standards in four axes, namely, respect for the elder people, midlevel care delivery, evidence-based care delivery, and promotion of active and healthy lifestyles [26]. In line with realizing goals, this program introduces five main infrastructures, one of which is developing an integrated information system for the older peoples. Considering the significance of implementing the information system and to develop a comprehensive and effective information infrastructure to support the NSF strategy, the U.K. Department of Health developed ISOP (Information Strategy for Older People) Strategy [27]. This strategy was developed based on a general strategy called "information for health and information for social care". The ISOP strategy fully covers the information needs pertaining to elderly people and a service specified in the NSF and ensures that developing an integrated information system based on this strategy can support comprehensive service delivery to the older peoples [27].

This program investigated the existing status of the older peoples' information system and identified challenges and shortcomings in this respect, including the need for the elderlies' service integration, the breakdown of existing information systems, lack of investment and participation in relation to the communication systems, lack of ease of sharing and information exchange in the caring process for the older people [27]. Regarding the shortcomings and the existing status of the current information systems, this strategy identified prospects in the form of 3 axes, namely, information for patients, care providers and the public; information to support care; and information to support clinical governance, performance monitoring and health improvement The study determined operational plans at national and local levels to realize each of the perspectives [27].

\section{Older people's information system in Ireland}

Ireland developed national strategy for the older population named "The Care of the Aged" for the first time in 1968, where policies were made to move towards community-based care rather than the hospital care [28]. After 20 years, they developed a strategy called "The years ahead: a policy for the elderly", which reemphasized the significance of community-based care and perused goals regarding the establishment and management of services to the older population [29]. In 2006, the Irish government developed a 10-year comprehensive program called "Towards 2016". This program belonged to the whole population and partly for the older people [30].

In 2016, the country developed a comprehensive program called "Healthy Ireland" for all sectors of society, aiming at developing a community-based approach [31]. It included different strategies in relation to various areas, one of which was related to the older people entitled "The National Positive Ageing Strategy" developed by a CDG (Cross-Departmental Group) comprising of representatives of the Department of Health, the Central Statistics Office and other related organizations. The officials developed the "National Positive Ageing Strategy" at the national level to promote the health, well-being and quality of life of older peoples, and specified policies and processes related to the integrated service delivery in regard with the older people issues [31]. In this strategy, they emphasized the significance and necessity of a comprehensive information system and determined the development of an information infrastructure for the older people as one of the goals. In this regard, with the participation of NCAOP (National Council on Ageing and Older People), DoHC (Department of Health and Children) and other relevant organizations, the Irish department of Health developed a comprehensive information framework for the older population. The program mainly aimed at developing a national proposal framework for guiding and prioritizing the data collection on the older people, where policies and plans were set in the form of short-term and long-term goals and priorities. Within the framework, researchers investigated the information needs related to the older people and identified shortcomings and requirements in this regard. Incomplete information about older people, the need to enhance the relationship between the existing data sources, the need to implement a standard approach to record and manage data, and the need to develop a comprehensive information system for the older people were among the issues addressed in this strategy [28].

In this framework, information on the older population were categorized into seven broad domains including demographic (DEM), education, training and the labor market(LAB); environment, housing, transport, safety and security (ENV); household, family and social relationships (FAM); health and healthcare (HEA); income, wealth and poverty (including social welfare payments and allowances) (INC); and social and social care (SOC) [28].

\section{Older people's information system in New Zealand}

In 2000, the Ministry of Health set out the Health of Older People Strategy to improve health services for older people [32] in which 8 general objectives and key steps for each of the objectives were indicated [33]. In this strategy, the Ministry put an emphasis on the significance of the existence of the information system for the older people and specified the key steps on developing a 
national information network and established a comprehensive information system. The information within this strategy comprised of the sociodemographic characteristics of the New Zealand older population; older people's health status; per capita older people's health; and expenditure on and older people's utilization of ACC services [32]. This strategy identified the existing status of the elderly's information system and shortcomings and needs in this regard including but not limited to: developing a national network strategy to improve the quality and accelerating the communications between health care organizations and information sharing support, improving the accuracy of the National Health Index (NHI) as a means of linking episodes during service delivery, and developing a comprehensive data collections on the elderly [32].

Considering the current shortcomings and in order to realize the older people's health strategy, the officials in the New Zealand developed a strategic plan called "Health of Older People Information Strategic Plan". In consultation with the District Health Boards (DHBs), the service provider representatives developed this Strategy in 2004, which aimed at determining a comprehensive plan for developing information infrastructure and information systems required for supporting and monitoring the services delivered to the older peoples [32]. Actually, the strategic plan aimed at ensuring that the information needed for the older people is well provided and that the information system meets the expectations and needs identified in the older people health strategy [32].

\section{Results}

Among the 30 studies investigated, 14 were related to integrated care plans and strategies of older people in various countries. While highlighting the positive outcomes of integrated care of the older people, all of these programs emphasized the need for an integrated information system which was identified as one of the main objectives of the program [15,26,31,32,3443]. The existence of an information system was raised as one of the requirements in the national framework provided by the UK Department of Health [27]. In the older people Care Program in the European Network (CARMEN) and the framework provided by Coudner et al. as well as the framework provided by Lutz, the existence of an information system was considered as one of the main features of the comprehensive older people care [15,41,42]. In 3 cases of the national-level programs, developing a comprehensive information infrastructure and the national network for the older people's information were identified as one of the key objectives and measures of the program $[27,31,32]$.

\begin{tabular}{|c|c|c|c|}
\hline Study Features/ Study & Country & The purpose of the study & Result \\
\hline $\begin{array}{l}\text { The IANUS Health } \\
\text { Information System [44] }\end{array}$ & Spain & $\begin{array}{l}\text { Delivering better and integrated services } \\
\text { to the older peoples }\end{array}$ & $\begin{array}{c}\text { Enhancing health care processes and better and timely access } \\
\text { of healthcare experts to information and continuously and } \\
\text { consistently delivering services to individuals. }\end{array}$ \\
\hline $\begin{array}{l}\text { The NEXES Information } \\
\text { System [45] }\end{array}$ & Spain & $\begin{array}{l}\text { Developing an information system with } \\
\text { the aim of delivering care services to the } \\
\text { older people }\end{array}$ & $\begin{array}{l}\text { Delivering integrated services to the older peoples, better } \\
\text { training for the older peoples regarding rehabilitation and } \\
\text { enhancement of their physical activity and reduction of } \\
\text { admission rate of the older peoples. }\end{array}$ \\
\hline $\begin{array}{l}\text { The Yorkshire and } \\
\text { the Humber Regional } \\
\text { Telehealth Hub [46] }\end{array}$ & $\begin{array}{l}\text { United } \\
\text { Kingdom }\end{array}$ & $\begin{array}{l}\text { Delivering patient care at home and } \\
\text { preventing unnecessary outpatient visits } \\
\text { and hospitalizations, increasing self-care } \\
\text { and reducing costs. }\end{array}$ & $\begin{array}{c}\text { Increasing patients' satisfaction, reducing hospital admissions } \\
\text { by } 20 \% \text {, and reducing hospital stay by } 30 \% \text { and, by and large, } \\
\text { providing quality services and reducing costs. }\end{array}$ \\
\hline $\begin{array}{l}\text { The National Telecare } \\
\text { Development program } \\
\text { [47] }\end{array}$ & $\begin{array}{l}\text { United } \\
\text { Kingdom }\end{array}$ & Delivering services to the older people & $\begin{array}{l}\text { Positive effects in delivering quality services to the older } \\
\text { people }\end{array}$ \\
\hline $\begin{array}{c}\text { The Integrated } \\
\text { Medicines Management } \\
\text { [48] }\end{array}$ & Ireland & $\begin{array}{l}\text { Better delivery of health services to the } \\
\text { older people based on their needs and } \\
\text { their timely, safe and high-quality access } \\
\text { to medical services }\end{array}$ & $\begin{array}{l}\text { Reducing the length of the patients' stay, providing quality } \\
\text { services and reducing costs }\end{array}$ \\
\hline $\begin{array}{l}\text { The Shared Care system } \\
\qquad[49]\end{array}$ & Denmark & $\begin{array}{l}\text { Delivering comprehensive services to the } \\
\text { older people, facilitating the exchange } \\
\text { of health information and enhancing } \\
\text { coordination }\end{array}$ & $\begin{array}{l}\text { Providing quality services, reducing costs and integrating the } \\
\text { information flow }\end{array}$ \\
\hline $\begin{array}{c}\text { The Dossier } \\
\text { Pharmaceutique } \\
\text { Information System [50] }\end{array}$ & France & $\begin{array}{l}\text { Developing an electronic pharmaceutical } \\
\text { record generative system }\end{array}$ & $\begin{array}{l}\text { Reducing drug interactions and a better managing of chronic } \\
\text { diseases in older people }\end{array}$ \\
\hline Guo Y [51] & Taiwan & $\begin{array}{l}\text { Developing an older people's } \\
\text { information system based on the } \\
\text { Comprehensive geriatric assessment } \\
\text { (CGA) program }\end{array}$ & $\begin{array}{l}\text { Improving the quality of care and managing the information } \\
\text { related to the older people, providing quality services and } \\
\text { reducing costs }\end{array}$ \\
\hline Guo Y \& Bai G [4] & Sweden & $\begin{array}{l}\text { Delivering a public architecture to } \\
\text { develop an e-health system for the older } \\
\text { people }\end{array}$ & $\begin{array}{l}\text { Developing a system based on the architecture model delivers } \\
\text { integrated services and interoperability of systems }\end{array}$ \\
\hline Vanneste D [52] & Belgium & $\begin{array}{c}\text { Developing an information system } \\
\text { under the title BelRAI based on InterRAI } \\
\text { schedule }\end{array}$ & $\begin{array}{l}\text { Using this information system improves the quality of older } \\
\text { people's comprehensive and integrated services. }\end{array}$ \\
\hline
\end{tabular}




\begin{tabular}{|c|c|c|c|}
\hline Fisher T [29] & Canada & $\begin{array}{c}\text { Developing an integrated information } \\
\text { system for the older people }\end{array}$ & $\begin{array}{c}\text { Using this information system facilitates the exchange of } \\
\text { information, increases coordination and improves the quality } \\
\text { of care. }\end{array}$ \\
\hline Kanaan S [33] & United states & $\begin{array}{c}\text { An intelligence system for the older } \\
\text { people called "SUMMA" }\end{array}$ & $\begin{array}{c}\text { Employing this system will deliver comprehensive care and } \\
\text { reduce hospital visit and costs. }\end{array}$ \\
\hline Sanchez A et al. [53] & Spain & $\begin{array}{c}\text { Developing an integrated information } \\
\text { system for comprehensive care of the } \\
\text { older people }\end{array}$ & $\begin{array}{c}\text { Improving care, better access to information and further } \\
\text { coordination }\end{array}$ \\
\hline
\end{tabular}

Additionally, researchers in 13 studies investigated the effect of the older people's information system on comprehensive service delivery. Table 1 briefly presents the findings. Among the 13 implemented information systems, 10 were implemented in European countries and the rest in the US, Canada, and Taiwan. Based on the results of all studies, using information systems has a key role in realizing the comprehensive care of the older peoples, and leads to the better management of the older peoples, quality service delivery and reduced costs (Table 1).

Based on the studies conducted, the programs related to the older people's information system specify features related to older people's information system, which is indicated in (Table 2).

\begin{tabular}{|c|c|c|c|}
\hline Features/ Countries & England & Ireland & New Zealand \\
\hline Accessibility to comprehensive information on older people at any time and place & $\checkmark$ & $\checkmark$ & $\checkmark$ \\
\hline Focusing and supporting the delivery of integrated care for the older people & $\checkmark$ & $\checkmark$ & $\checkmark$ \\
\hline Possibility to support comprehensive assessments of the older people & $\checkmark$ & - & $\checkmark$ \\
\hline Possibility to exchange information with the required standards and security protocols & $\checkmark$ & $\checkmark$ & $\checkmark$ \\
\hline Developing aging data sets at the national level & $\checkmark$ & $\checkmark$ & $\checkmark$ \\
\hline $\begin{array}{l}\text { Communicability and integration with a variety of information sources, databases and } \\
\text { registry systems related to aging. }\end{array}$ & $\checkmark$ & $\checkmark$ & $\checkmark$ \\
\hline $\begin{array}{l}\text { The existence of a common language and the possibility of sharing information among } \\
\text { different individuals and organizations aimed at delivering integrated care. }\end{array}$ & $\checkmark$ & $\checkmark$ & $\checkmark$ \\
\hline Developing an integrated electronic record for older people & $\checkmark$ & $\checkmark$ & $\checkmark$ \\
\hline Developing CDSSs and accessing to evidence-based information & - & - & $\checkmark$ \\
\hline Provision of a comprehensive reporting system & $\checkmark$ & $\checkmark$ & $\checkmark$ \\
\hline $\begin{array}{l}\text { The possibility of continuous monitoring and supervising health and social services } \\
\text { delivered to the older people aimed at enhancing the efficiency and quality of services }\end{array}$ & $\checkmark$ & $\checkmark$ & $\checkmark$ \\
\hline Developing a comprehensive and central database & $\checkmark$ & $\checkmark$ & $\checkmark$ \\
\hline
\end{tabular}

\section{Conclusion}

Delivering integrated and comprehensive health care services to the older people play a significant role in improving the quality of service delivery, optimizing the use of health resources and reducing costs $[6,11,12]$. On this basis, and to deliver integrated services to the older people, countries plan to adopt policies in this regard. Based on the results of investigations, these programs mostly had a positive effect on cost reduction and quality of care. In order to deliver comprehensive and integrated services to the elderly, various organizations, namely, hospitals, Welfare Organization, older adults care centers, older people counseling centers, rehabilitation centers and psychological centers must work cooperatively together $[7,16-18]$. Actually, these organizations and the care team should be able to easily exchange information and make the necessary coordination. Information systems can play a significant role in making effective communication between care providers. Due to their capabilities, these systems will lead to better coordination and facilitation of the exchange of information among organizations $[7,20]$. Also, the care team can better gain access the information related to the older people and share the experiences, knowledge and information available based on the information system $[4,9,11,22]$ which can lead to making the right decisions and deliver quality services to the older people $[7,24]$. Without an integrated health information system, healthcare professionals will face a variety of problems, namely, rework, increased workload, increased data duplicates, and waste of time [54]. Many developed countries, especially European countries, have implemented and used these technologies in their agenda due to the benefits of using information technology and information systems for the elderly $[44,46,49,50]$. Developing a comprehensive information infrastructure and national information network for the older people is an issue emphasized in the developed strategies [27,31,32]. Developing such an infrastructure is the basis for designing a comprehensive information system for the older people, which leads to its principled and effective design. Based on the investigations, there are various information sources and databases concerning the elderly. The integrated information system for the older people should be able to communicate with these resources and exchange information. Designing and developing a dataset regarding the older people and developing 
a common language are deemed necessary as well. Specifying the data set at the national level leads to a single approach to data collection and enhances the quality of data, which will also facilitate the exchange of information among organizations [27,28,32]. Older people's information security and privacy and information confidentiality are important issues that need to be considered in designing the older people's information system. Developing older people's electronic record is another issue mentioned in the studied programs [27]. An integrated electronic health record containing the entire health and social information of an individual can play a crucial role in enhancing care delivery and delivering integrated care in general. Thus, the information system for older people should be designed to produce an electronic health record for the elderly. Another requirement of the older people's information system was a reporting system and the continuous monitoring and supervising of services, which allows managers and policymakers to have permanent access to the essential information and continually monitor issues such as quality of service, older people's access to care services, leading to proper decision making [28]. It can actually be effective in enhancing the quality, management, planning and policy-making.

To conclude, developing information systems as one of the infrastructures of integrated care programs can play a significant role on the realization of continuous and comprehensive care for the older people. Considering the growing population of older people in societies and the conditions dominating their social and health conditions that require a wide range of continuous and integrated care, and based on the significance and role of information systems in the realization of comprehensive care of the elderly, designing and implementing an integrated information system is deemed necessary. Developing a comprehensive information infrastructure and identifying the features of the information system for the older people can remarkably affect the principled and efficient design of the information system.

\section{Competing Interests}

The authors declare that they have no competing interests.

\section{References}

1. Ocampo JM (2010) Self-rated health: Importance of use in elderly adults. Colombia Médica 41(3): 275-289.

2. WHO, International Day of Older Person (2016).

3. United Nations, Department of Economic and Social Affairs, Population Division. World Population Prospects: The 2015 Revision, Key Findings and Advance Tables. Working Paper No. ESA/P/WP.241, 2015.

4. Guo Y, Bai GA (2014) General architecture for developing a sustainable elderly care e-health system. International Journal of Information Technology and Business Management 27(1).

5. Shabat S, Arinzon Z, Folman Y, Leitner J, David R, et al. (2008) Longterm outcome of decompressive surgery for Lumbar spinal stenosis in octogenarians. Eur Spine J 17(2): 193-198.

6. Chan H, Cheng SH, Su H (2008) Integrated care for the elderly in the community. International Journal of Gerontology 2(4): 167-171.

7. Vedel I, Akhlaghpour S, Vaghefi I, Bergman H, Lapointe L (2013) Health information technologies in geriatrics and gerontology: a mixed systematic review. J Am Med Inform Assoc 20(6): 1109-1119.
8. Graham Ellis, Martin A Whitehead, David Robinson, Desmond O'Neill, Peter Langhorne (2011) Comprehensive geriatric assessment for older adults admitted to hospital: meta-analysis of randomised controlled trials. BMJ 343: d6553.

9. Mouratidis H, Manson1 G, Giorgini P, Philp I Modelling an agent-based integrated health and social care information system for older people. Computer Science Department, University of Sheffield \& Sheffield Institute for Studies on Ageing (SISA), England.

10. Béland F, Hollander MJ (2011) Integrated models of care delivery for the frail elderly: international perspectives. Gac Sanit 25(S2): 138-146.

11. MacAdam M (2008) Frameworks of Integrated Care for the Elderly: A Systematic Review, CPRN Research Report. Canadian Policy Research Networks Inc.

12. National Voices (2013) Integrated care: what do patients, service users and careers want?

13. Centre for workforce intelligence (2011) Integrated Care for Older People: Examining Workforce and Implementation Challenges.

14. Hofmarcher M, H Oxley, E Rusticelli (2007) Improved Health System Performance through Better Care Coordination.

15. P (2004) Policy framework for integrated care for older people developed by the Carmen Network. London: King's Fund.

16. Royal College of Physicians. Future hospital: caring for medical patients. A report from the Future Hospital Commission to the Royal College of Physicians. London: Royal College of Physicians.

17. Cornwell J (2012) The care of frail older people with complex needs: time for a revolution. London: The King's Fund.

18. Imison C, Bohmer R (2013) NHS and social care workforce: meeting our needs now and in the future? The King's Fund, London, p. 1-10.

19. Hagglund M (2009) Sharing is Caring, Integrating Health Information Systems to Support Patient-Centred Shared Homecare. Int J Integr Care 9: e11.

20. Mwanyika H B (2014) Developing integrated health information systems in low income countries: An enterprise architecture approach.

21. Henry J (2001) Clinical diagnosis and management by laboratory methods. $\left(20^{\text {th }}\right.$ Edn) Vol 1 USA.

22. Oliver D, Foot C, Humphries R (2014) Making our health and care systems fit for an ageing population.

23. Tomasi E, Facchini LA, Maia MF (2004) Health information technology in primary health care in developing countries: a literature review. Bull World Health Organ 82(11): 867-874.

24. Lamine E, Zefouni S, Bastide R, Pingaud H (2014) A System Architecture Supporting the Agile Coordination of Homecare Services Collaborative Networks for a Sustainable World. IFIP Advances in Information and Communication Technology.

25. Maddox GL, Blazer D, Laurie WF (1981) Applications of an information system for geriatric planning.

26. Department of Health. National service framework for older people. STEVENSON, E, NH3171; 2001.

27. Department of Health. Information Strategy for Older People in England. STEVENSON, E., NH3171.; 2002.

28. National Council on Ageing and Older People (2006). The development of a draft framework for the collection of information about the older population. National Council on Ageing and Older People: Economic and Social Research Institute, Dublin.

29. Fisher T. Development of the Integrated Patient Information System for the Geriatric Day Hospital at the QEII.

30. Department of the Taoiseach (2006). Towards 2016 Ten-Year Framework Social Partnership Agreement 2006-2015. Stationery Office: Dublin. 
31. Department of Health (2013) Positive Ageing Starts Now! National Positive Ageing Strategy.

32. Ministry of Health (2006) Health of Older People Information Strategic Plan: Directions to 2010 and beyond. Wellington: Ministry of Health.

33. Kanaan Susan B (2009) Homeward Bound: Nine Patient-Centered Programs Cut Readmissions. California HealthCare Foundation.

34. Andrews KJ (2001) National strategy for an ageing Australia: An older Australia, challenges and opportunities for all. Canberra: Department of Health and Aged Care.

35. US Department of Health and Human Services, Substance Abuse and Mental Health Services Administration. National Registry of EvidenceBased Programs and Practices. Intervention Summary: Program for AllInclusive Care for the Elderly (PACE).

36. Leung AC, Liu C, Chow NW, Iris Chi (2004) Cost-benefit analysis of a case management project for the community-dwelling frail elderly in Hong Kong. J Appl Gerontol 23: 70-85.

37. Hollander MJ, Chappell N (2007) A comparative analysis of costs to government for home care and long-term residential care services, standardized for client care needs. Can J Aging 26 (S1):149-161.

38. Hébert R, Raîche M, Dubois MF, Gueye NR, Dubuc N, et al. (2010) Impact of PRISMA, a coordination-type integrated service delivery system for frail older people in Quebec (Canada): a quasi-experimental study. J Gerontol B Psychol Sci Soc Sci 65B(1):107-118.

39. Applebaum R, Straker J, Mehdizadeh S, Warshaw G, Gothelf E (2002) Using high-intensity care manage- ment to integrate acute and longterm care services: substitute for large scale system reform? Care Manag J 3(3): 113-119.

40. Centers for Medicare and Medicaid Services (2015) Long-term Care Facility Resident Assessment Instrument 3.0 User's Manual, Version 1.13. Atlanta, GA: Centers for Medicare and Medicaid Services.

41. Kuo NW, Chung YY (2012) The application of healthcare information system for comprehensive geriatric assessment. MIS REVIEW: An International Journal 17(2): 87-98.

42. Vanneste D, Vermeulen B, Declercq A (2013) Healthcare professionals acceptance of BelRAI, a web-based system enabling person-centred recording and data sharing across care settings with interRAI instruments: a UTAUT analysis. BMC medical informatics and decision making 13(1):129.

43. Béland, F, H Bergman, P Lebel, M Clarfield, Tousignant P, et al. (2006) A System of Integrated Care for Older Persons with Disabilities in Canada: Results from a Randomized Control Trial. The Journals of Gerontology; Series A: Biological Sciences and Medical Sciences 61(4): 367-374.

44. European Innovation Partnership on Active and Healthy Ageing. Excellent innovation for ageing A European Guide. European Commision. 2013.

45. Hernandez C, Alonso A, Garcia Aymerich J, Grimsmo A, Vontetsianos T, et al. (2015) Integrated care services: lessons learned from the deployment of the NEXES project. International journal of integrated care 15(1).

46. Cruickshank J, Paxman J (2013) Yorkshire \& the Humber Telehealth Hub. 2020Health.org.

47. Newhaven research. The Telecare Development Programme in Scotland 2006-11. 2011.

48. http://www.dhsspsni.gov.uk

49. http://www.regionsyddanmark.dk/wm258038, improvingchroniccare.org

http://www.

50. Pharmaceutical Group of European Union (2016) eHealth Solutions in European Community Pharmacies: Annex. Pharmaceutical Group of European Union.

51. Kuo N (2011) Information Technology Applications for Geriatric Consultation Services in Taiwan. International Journal of Advancements in Computing Technology 3(1).

52. Vanneste D, Declercq A (2014) The development of BelRAI, a web application for sharing assessment data on frail older people in home care, nursing homes and hospitals. Achieving effective integrated E-care beyond the silos. IGI Global, Hershey, PA, USA pp. 202-226

53. Sánchez A, Villalba Mora E, Peinado I, Rodriguez Mañas L (2016) Integrated Care Program for the very old adults. International Journal of Integrated Care 16(6).

54. Sajid M, Ahsan K (2016) Role of enterprise architecture in healthcare organizations and knowledge-based medical diagnosis system. Journal of Information Systems and Technology Management 13(2): 181-192. 